\title{
ARTICLE
}

\section{The care, treatment, rehabilitation and legal outcomes of referrals to a tertiary psychiatric hospital according to the Mental Health Care Act No. 17 of 2002}

\author{
D P Madlala, MB BCh, DMH (SA), MMed (Psych); F B Sokudela, MB ChB, MMed (Psych) \\ Department of Psychiatry, School of Medicine, Faculty of Health Sciences, University of Pretoria, South Africa
}

Corresponding author: F B Sokudela (funeka.sokudela@up.ac.za)

Background. The Mental Health Care Act No. 17 of 2002 (MHCA) was introduced to combat poor care received by mentally ill persons. Objective. The objective of this study was to evaluate diagnostic and treatment accuracy as well as compliance with procedural matters related to the MHCA, using a sample in the northern region of Gauteng Province, South Africa.

Method. Files of 200 patients admitted to Weskoppies Hospital between June and December 2009 were evaluated for admission procedures, and care, treatment and rehabilitation (CTR).

Results. From referring hospitals, 174 (87\%) persons had appropriate signs and symptoms documented in the referral note or MHCA forms. All of these were appropriately diagnosed. Although about one-third of the patients' treatment was not documented, more than $50 \%$ ( $n=163$ ) received the correct treatment. In two-thirds of patients, correction of detected abnormalities was not documented. Approximately $50 \%$ of the admissions had documents that did not adhere to MHCA provisions. At Weskoppies Hospital, CTR was considered appropriate for $92 \%$ of the patients. The legal status of the majority of patients was involuntary at discharge point. The majority of persons stayed for $<3$ months but for longer than what medical aid schemes allow in the private sector.

Conclusions. The study highlighted both improvements and gaps in CTR given to mentally ill persons in the northern Gauteng region, which might apply to the rest of the country. Medicolegal requirements stipulated by the MHCA are still a challenge a decade post enactment, but there may be a move in the right direction.

S Afr J Psychiatr 2014;20(4):172-176. DOI:10.7196/SAJP.496

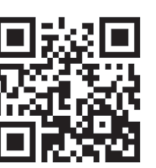

When psychiatry burgeoned as a medical discipline in the 19th century, the quality of care and treatment given to mentally ill persons worldwide was unsatisfactory. The mentally ill were confined in asylums, and the living conditions therein were characterised by overcrowding, shortage of human resources and lack of treatment. Stigma, discrimination and isolation were also prevalent. ${ }^{[1-3]}$ In the 20th century there was, however, a slight paradigm shift from strictly ostracised and isolated inpatient care to a more decentralised form of care based at community level, which sought to empower affected individuals. Despite this move, neuropsychiatric disorders still comprise $13 \%$ of the global disease burden. ${ }^{[4]}$ Research continues to reveal poor-quality care given to mentally ill persons globally. ${ }^{[5]}$ In many facilities, inpatient care has been subjected to criticism, ${ }^{[5-10]}$ and care has been described as lacking containment and management in some settings. ${ }^{[11]}$ Attitudes of healthcare practitioners (HCPs) towards mentally ill persons largely contribute to this poor care, and research shows that mental HCPs (MHCPs) perpetuate the stigma attached to mental illness through negative attitudes. ${ }^{[12,13]}$ These negative attitudes translate to poor clinical management of patients. Some patients are denied proper physical work-up, including history taking, physical examination and laboratory investigations, on the basis of being mentally ill. ${ }^{[14-16]}$ The poor levels of care result in lack of detection of natural diseases and non-treatment. This in turn leads to a high rate of mortality from natural diseases in mentally ill people compared with the general population. ${ }^{[17]}$

South Africa (SA) is not exempt from these findings regarding poor treatment given to mentally ill persons. Williams et al ${ }^{[18]}$ found that $75 \%$ of people living with mental disorders in SA do not receive the care they need. After adopting its new Constitution in 1996, SA also needed to incorporate the care of mentally ill persons within the required principles of the protection of human rights and human dignity. ${ }^{[19]}$ The Mental Health Care Act No. 17 of 2002 (MHCA) ${ }^{[20]}$ was promulgated in 2004 and contains provisions that are based on these principles. The MHCA seeks to ensure that appropriate care, treatment and rehabilitation (CTR) are provided, and promotes the rights and interests of mentally ill persons. It also promotes provision of community-based care. In terms of admission procedures, the emphasis is on full assessment of a mentally ill person both physically and psychologically. The MHCA also allows for treatment to be initiated as soon as possible and referral of persons still in need of inpatient care after 72 hours to psychiatric facilities.

Although the MHCA has good intentions, whether its objectives can be fully applied in clinical settings is questionable. Research done in SA has pointed to problems with infrastructure and human resources 
as impediments to the accomplishment of these objectives. ${ }^{[21-23]}$ There are scant data in the country regarding the effect of the MHCA since its promulgation, in improving the care given to mentally ill persons. Nonetheless, a survey carried out in KwaZulu-Natal has shown some degree of improvement in care. ${ }^{[24]}$

The current study measured the effect of the MHCA by selecting a sample in a specific region of northern Gauteng and focusing on the following aspects of care: the way diagnoses were formulated; the appropriateness of the treatment provided; the correction of abnormal results of investigations; the quality of record-keeping; and compliance with the procedural matters of the MHCA. All of the above were evaluated at Weskoppies Hospital, as well as length of stay and the legal status at discharge point.

The study received approval from the Research Ethics Committee of the Faculty of Health Sciences, University of Pretoria. A waiver of informed consent was obtained from Weskoppies Hospital authorities.

\section{Methods}

A retrospective descriptive study was carried out from October 2011 to August 2012. Clinical files of the first 200 mental healthcare users admitted to Weskoppies Hospital - a specialised tertiary-level referral hospital in the Tshwane region - between June and December 2009 were retrospectively reviewed. A unique number was assigned to each file to obscure the identity of individuals to maintain confidentiality. The study included males and females aged $>18$ years, who were admitted with an involuntary or assisted status.

A data collection sheet used to capture information was divided into three subsections: section A comprised demographic and referral details; section $\mathrm{B}$ comprised clinical information from referring secondary-level hospitals in the region; and section $\mathrm{C}$ comprised data on clinical information from Weskoppies Hospital that was similar to that collected from the referring hospitals. For section $\mathrm{B}$, the following were extracted from MHCA forms 05 and 06 from the referring hospitals: the appropriateness of the signs and symptoms documented; the appropriateness of the diagnosis given; and whether the documentation procedure complied with the requirements of the MHCA.
For the purposes of this study, the Diagnostic and Statistical Manual of Mental Disorders, 4th edition (text revised) (DSM-IV-TR) diagnostic criteria were used to assess the appropriateness of signs and symptoms. According to the DSM-IV-TR, symptoms are grouped together to make up a criterion for a particular disorder. Symptoms used to formulate a diagnosis for a particular disorder were assessed for uniformity with the symptoms described in the DSM-IVTR criteria for that particular disorder. Appropriate symptoms were those that met the criteria described by DSM-IV-TR for a particular diagnosis; inappropriate symptoms were those that did not meet the criteria. Documentation procedure in line with the MHCA was defined as fulfilling all the requirements regulated by the MHCA. From the MHCA 04 form, demographic data of the mentally ill person must be documented, including details of the person applying and the reasons for the application. MHCPs must fill in the required documents in a manner as regulated by the MHCA. ${ }^{[14]}$ The treatment was appropriate if it was in keeping with treatment outlined by treatment guidelines generally accepted in clinical practice locally, e.g. based on the American Psychiatric Association Practice Guidelines. ${ }^{[25]}$ Investigations done were evaluated for correct management of abnormalities, if these were detected. The same information was evaluated at Weskoppies Hospital. In addition, the legal status at admission was compared with status at discharge, and the length of stay was measured.

\section{Statistical analysis}

Descriptive statistics were used to analyse data. To determine associations between variables, Pearson's $\chi^{2}$ test was used, and where data were small, Fisher's exact test was used.

\section{Results}

The first 200 files that met the inclusion criteria were taken from a pool of 1000 files. The sample size was considered appropriate for the population, and convenience sampling was applied. Table 1 outlines the demographics of the sample. The majority of referrals came from Kalafong Hospital (39\%), followed by Mamelodi Hospital (23\%) and Tshwane District Hospital (22\%) (Table 2). Medical officers at these secondary-level hospitals are trained in basic psychiatry up to a general practitioner level. They consult and refer to specialist and trainee psychiatrists at the tertiary-level hospital in the region, namely Weskoppies Hospital. Although later trends may differ, only one referral came from Steve Biko Academic Hospital (a general hospital with a psychiatric unit). This may be partly because it was run by specialist psychiatrists during the study period.

\section{Care, treatment and rehabilitation at 72-hour facilities}

Appropriate symptoms and signs were documented in $174 / 200$ patients (87\%). The majority of patients received a diagnosis related to schizophrenia spectrum and other

\begin{tabular}{|c|c|}
\hline Characteristics & $\%$ \\
\hline \multicolumn{2}{|l|}{ Gender } \\
\hline Male & 68 \\
\hline Female & 32 \\
\hline \multicolumn{2}{|l|}{ Age (years) } \\
\hline $18-29$ & 46.5 \\
\hline $30-60$ & 49.5 \\
\hline$>60$ & 4.0 \\
\hline \multicolumn{2}{|l|}{ Marital status } \\
\hline Married & 76.0 \\
\hline Single & 9.5 \\
\hline Divorced & 6.0 \\
\hline Widowed & 4.5 \\
\hline Unknown & 4.0 \\
\hline \multicolumn{2}{|l|}{ Level of education } \\
\hline Never at school & 5.0 \\
\hline Special school & 5.0 \\
\hline Grades 1 - 4 & 3.0 \\
\hline Grades 5 - 7 & 5.5 \\
\hline Grades 8 - 12 & 16.0 \\
\hline Secondary specialised & 6.5 \\
\hline Postsecondary specialised & 4.0 \\
\hline Unknown & 62.5 \\
\hline
\end{tabular}

\begin{tabular}{ll} 
Table 2. Referring hospitals & \\
\hline Hospital & $\%$ \\
\hline One Military & 0.5 \\
Witbank & 0.5 \\
Pretoria West & 2.0 \\
Dr George Mukhari & 5.0 \\
Tshwane District & 22.0 \\
Mamelodi & 23.0 \\
Kalafong & 39.0
\end{tabular}




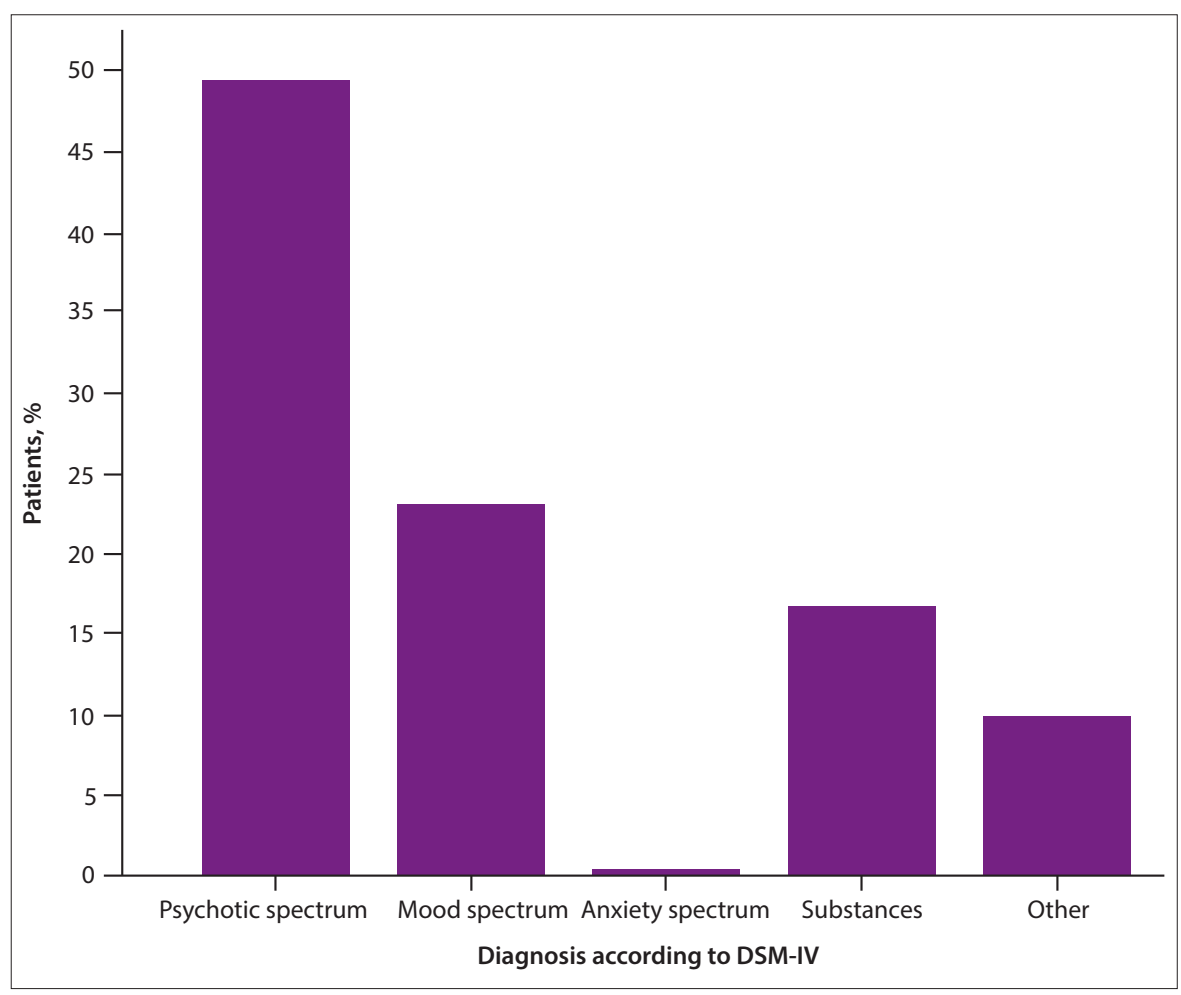

Fig. 1. Segregation of psychiatric disorders. (DSM-IV = Diagnostic and Statistical Manual of Mental Disorders, 4th edition.)

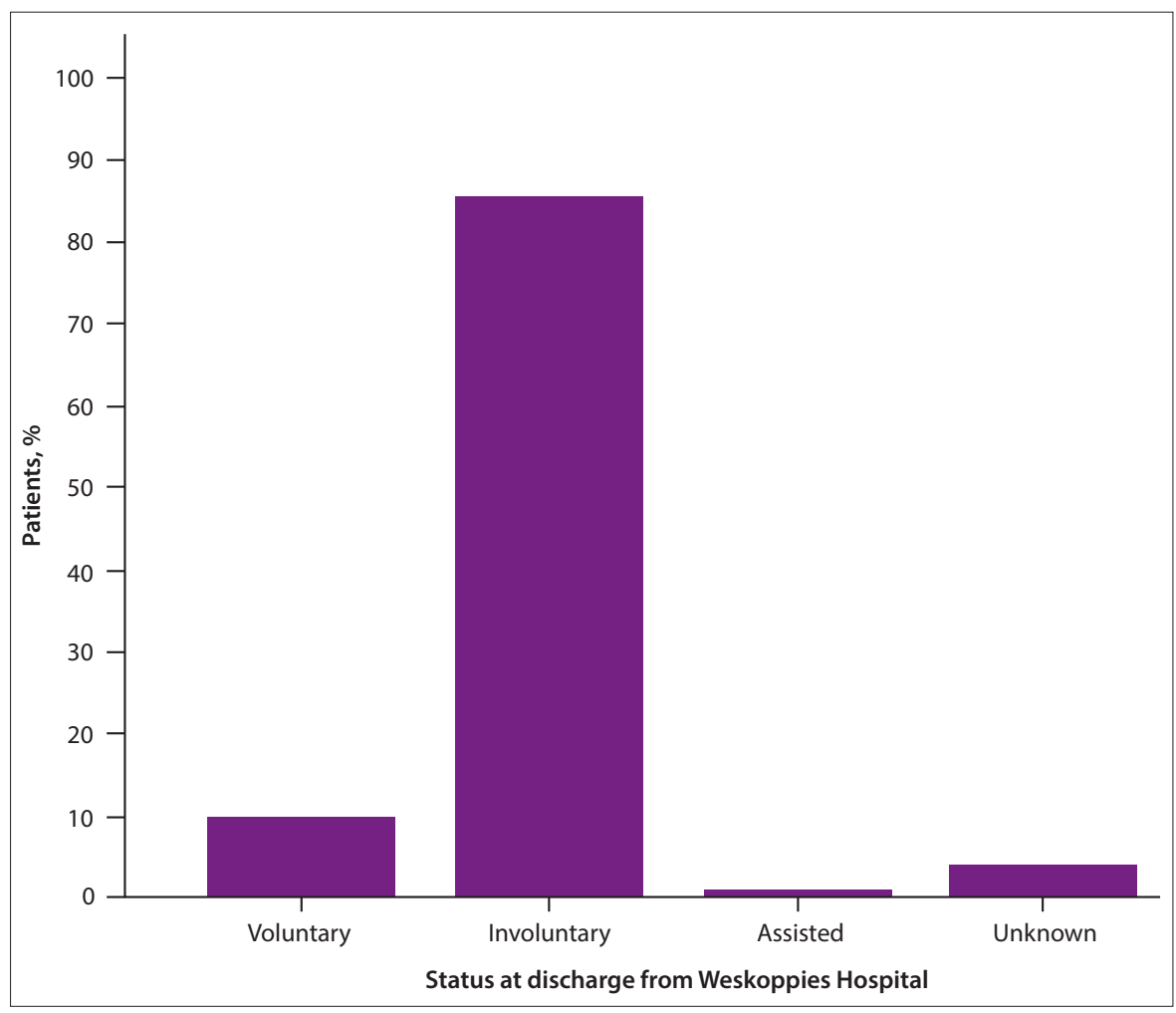

Fig. 2. Number of patients and status at discharge.

psychotic disorders (Fig. 1). The following symptoms, signs and their respective diagnoses were considered inappropriate as they were not in line with descriptive symptoms outlined by DSM-IV-TR for a particular diagnosis: confusion and disorientation prompting a diagnosis of psychosis; crying as the only symptom prompting a diagnosis of depression; hyperactivity prompting a diagnosis of substance-induced psychotic disorder; and pressured speech and mutism prompting a diagnosis of schizophrenia. In three files, no symptoms were outlined, a statement 'known psych patient' was given and the diagnosis was given as acute mental illness. Treatment was considered appropriate in 139 patients $(63 \%)$, as assumed of local practice. In one-third of patients, treatment given was not documented, and neither were abnormalities corrected that were detected from investigations. In $\sim 50 \%$ of files, the documentation procedure did not adhere to the requirements of the MHCA. In 34 files, the information regarding the past and present mental status of the patient as reported by the family was not written on the MHCA form 05. This information is pivotal and is needed for holistic understanding of the patient; it points out the previous treatment response of the patient and aids in the future management of the patient. Twenty-seven files had both spaces for assisted and involuntary application filled, making the application invalid and admission of the patient against his/her volition illegal (sections 26 - 34 of the MHCA for legal admission of mentally ill persons). In eight files, the same MHCP filled in both forms 05 and 06. It is clearly stated in the MHCA that the patient should be examined by two MHCPs (section 27(4)(a) and section 33(4) (a)). If one person completed both forms, this may indicate that only one person actually saw the patient and admission was on the basis of only one practitioner's findings. From one file, the physical status of the patient was described as average, which is vague. In 12 files, the forms were not filled in completely.

\section{Care, treatment and rehabilitation at Weskoppies Hospital}

The majority of individuals (92\%) received a correct diagnosis (according to DSMIV-TR criteria) and treatment. Six patients presented with abnormal results that were detected at Weskoppies Hospital and corrected. However, in four patients, abnormal urea and creatinine results found were not corrected at Weskoppies Hospital. Although adequate information was captured, it was not filed in a consistent 
manner in $60 \%$ of the files. This made it difficult to find some vital information at times. In one file, notes were not written in English, the official language of Weskoppies Hospital. This was assessed as inappropriate because information about the patient must be accessed by all clinicians, including those who do not understand SA languages other than English. Regarding discharge status, more than two-thirds were discharged as involuntary outpatients and only onetenth were discharged as voluntary mental healthcare users (Fig. 2).

Regarding length of hospital stay, the majority of patients stayed between 43 days and 90 days; only one-fifth stayed for $<21$ days. A significant association between the legal status at discharge and length of stay was found $(p=0.003)$, with involuntary status associated with a longer duration of stay (Fig. 3).

\section{Discussion}

The process of mental healthcare begins when a patient and his/her caregiver(s) seek help at a healthcare facility. Adequate levels of care are achieved through various means, including a careful exploration of symptoms and formulation of a correct diagnosis by those qualified to do so. Knowledge of symptoms and signs, and their correct analysis, are key steps towards the formulation of a diagnosis and the choice of treatment. ${ }^{[26]}$ In this study, the fact that the majority of individuals received a correct diagnosis is encouraging. This result is significant clinically, and probably indicates an improvement in the detection of psychiatric symptoms by nonpsychiatric doctors in this region. Golberg and Bidges ${ }^{[27]}$ previously found that most psychiatric diagnoses were missed by nonspecialists in this field. Margolis ${ }^{[28]}$ concurred with these findings, determining that in $68 \%$ of cases of depression diagnosed by non-psychiatric health practitioners, only $22 \%$ could be confirmed by a psychiatrist. Most non-psychiatric health practitioners failed to identify delirium and adjustment disorder in that study. Inappropriate symptoms that contributed to inappropriate diagnoses in the current study included use of confusion and disorientation to define psychosis. Hyperactivity and mutism were also used as criteria for the diagnosis of schizophrenia. The use of the term 'known

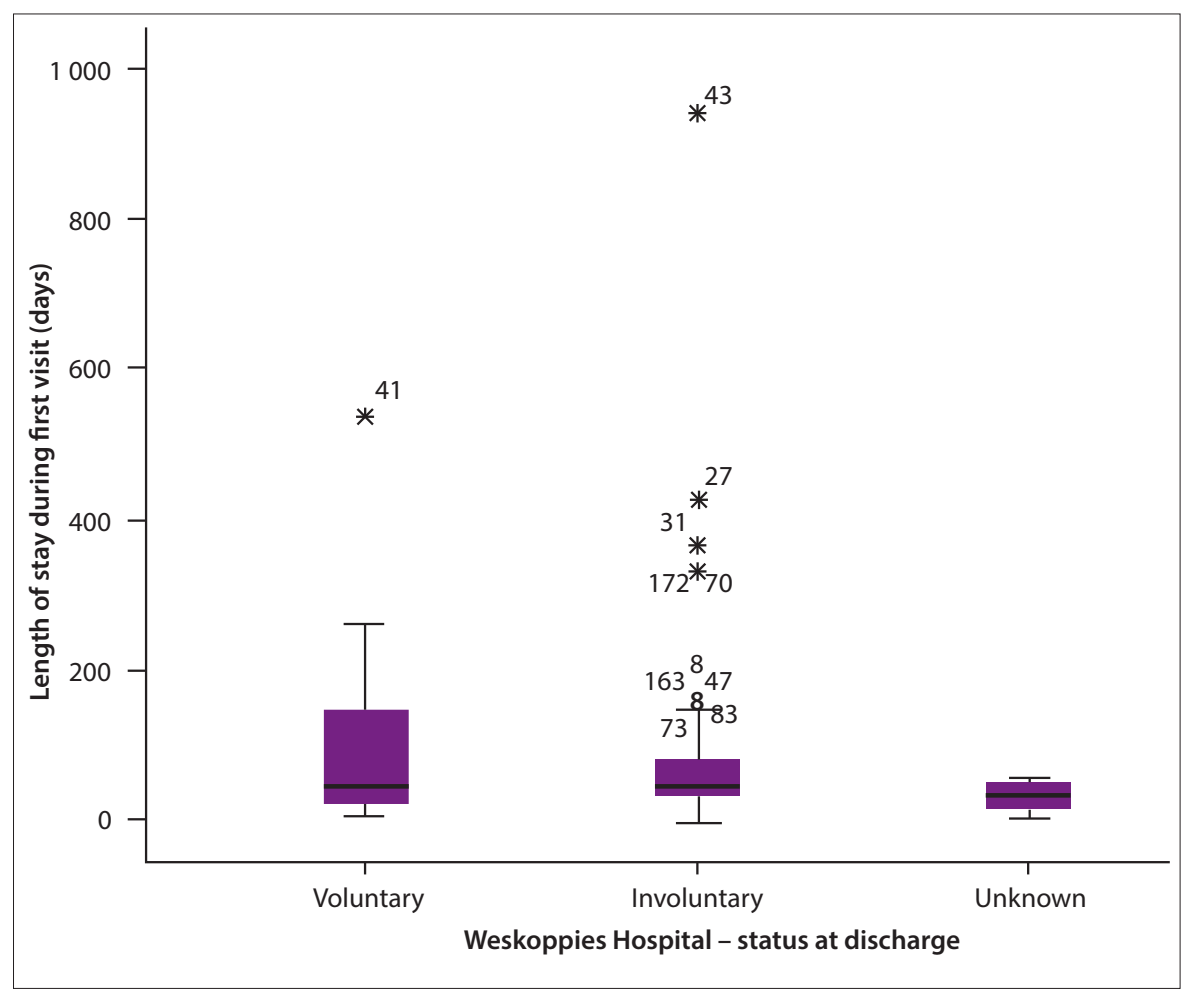

Fig. 3. Association between length of stay and status at discharge.

psych patient' instead of exploring current presenting symptoms was also prevalent. This signifies a need for continuous training of non-psychiatric health practitioners in identifying symptoms. Good clinical practice and good standards of care as promoted by the MHCA imply that all mental healthcare users, and not just the majority, must receive appropriate diagnoses. However, there may be complicated tertiary-level cases that would need specialised skills and multidisciplinary team efforts for a complete understanding of the patient. These cases would then be referred to a specialised psychiatric facility as in this study.

Regarding pharmacological treatment, the fact that a fair number of patients in the current study received a fully appropriate treatment is noted. This suggests an improvement, though somewhat modest, in pharmacotherapy given to mentally ill persons. In a study by Leslie and Rosenheck, ${ }^{[29]}$ more than one-third of patients were outside the recommended range of acceptable treatment. The treatment inappropriateness noted in the results may indicate the need for better continued medical education of medical practitioners at secondary-level facilities and perhaps more emphasis on the training of medical students in psychotropic pharmacology. Poor documentation noted in the current study is a drawback, as record-keeping is central to patient management and communication in a multidisciplinary system, helping to prevent negative healthcare outcomes by reducing miscommunication errors. Documentation procedures outlined in the MHCA need to be followed when patients are admitted, whether as involuntary or assisted mental healthcare users. The procedures detailed in the MHCA seek to ensure adequate and legal management of vulnerable persons whose rights to voluntary treatment are being temporarily withheld for therapeutic reasons and their greater good. Findings related to poor adherence to legal requirements and the documentation thereof in this study signify a breach of regulations. If MHCA forms are not properly completed, then admission is illegal and technically treatment ought not to be granted without the patient's consent. Medicolegal challenges emanating from this scenario are multiple. The omission of proper and legal documentation before referral creates problems at psychiatric facilities. The Mental Health Review Board (MHRB) of the region is appointed as caretaker of patients' rights and oversees 
legal admission processes. Any documentation that is not done according to the prescripts of the MHCA by the original hospital that bestows an involuntary status on the patient is rejected by the MHRB. The correction of these procedures on paper then becomes a strain on the tertiary-level psychiatric facility.

Factors related to involuntary status at discharge need further exploration. The findings may be reflecting the fact that at tertiary hospital level, people with more-severe mental illness are treated and that their admission and discharge status is affected by their degree of mental illness. Involuntary status at discharge, however, may also be reflective of the fact that these individuals' rights, to be converted to a less restrictive status of admission once their clinical condition improves, may not be observed according to chapter III of the MHCA. ${ }^{[20]}$

One of the more profound findings was related to length of stay. On the one hand, the relatively short length of stay signifies a move towards the requirements of the MHCA in that people are referred back to their communities sooner rather than later. On the other hand, the fact that a minority of patients stayed for fewer than the 21 days that is usually allowed in the private health sector by medical aid schemes ${ }^{[30]}$ is of concern. Factors related to the discrepancy in this area between the public and the private health sector will need to be explored in future studies. At face value, this finding signals a skew in the burden of treatment of mental healthcare users who need a hospital stay $>3$ weeks towards the public sector. Justice, equity and the human rights of users in terms of budget and human resource allocations in the private and public health sectors may have to be revisited once again, especially in light of the planned introduction of National Health Insurance within the next decade.

\section{Study limitations}

The study was a retrospective review and might have been subjected to recording bias. The data collection and capturing processes were reviewed by the second author and a statistics officer to lessen the margin of error. Another limitation is that the referrals came from different sources and the specific individual factors affecting the findings related to each institution were not quantified. This will be for a study of a different nature. The inverse of this is positive, however that a common thread could be drawn across secondary-level centres with similar levels of clinical and administrative expertise.

\section{Conclusion}

The study highlights both improvements and gaps in CTR given to mentally ill persons in the northern Gauteng region, which might apply to the rest of the country. Medicolegal requirements stipulated by the MHCA are proving to be a challenge, almost a decade after its enactment.

Acknowledgements. We extend our gratitude to J Jordaan (Department of Statistics, University of Pretoria) for electronic data management and analysis, and to B English for language editing of this manuscript.
References

1. World Health Organization. The World Health Report 2001 - Mental Health: New Understanding, New Hope. Geneva: World Health Organization, 2001.

2. Deacon HJ. Madness, race and moral treatment: Robben Island Lunatic Asylum, Cape Colony, 1846 - 1890. Hist Psychiatry 1996;7(26):287-297.

3. Novella EJ. Mental health care and politics of inclusion: A social system account of psychiatric deinstitutionalization. Theor Med Bioeth 2010;31(6):411-427. [http://dx.doi.org/10.1007/s11017010-9155-8]

4. Saxena S, Skeen S. No health without mental health: Challenges and opportunities in global mental health. Afr J Psychiatry 2012;15(6):397-400.

5. Muijen M. Mental health services in Europe: An overview. Psychiatr Serv 2008;59(5):479-482.

6. Bowers L, Chaplin R, Quirk A, Lelliott P. A conceptual model of aims and functions of acute inpatient psychiatry. J Ment Health 2009;18(4):316-325. [http://dx.doi. org/10.1080/09638230802053359

7. Mental Health Reform. Promoting Improved Mental Health Services. Dublin: Mental Health Reform, 2014. http://www.mentalhealthreform.ie/ (accessed March 2014).

8. Gillis L, Robertson BA, Zabow T, Stein DJ. No health without mental health: Establishing psychiatry as a major discipline in an African faculty of health sciences. S Afr Med J 2012;102(6):449-451

9. Suliman S, Stein DJ, Myer L, Williams DR, Seedat S. Disability and treatment of psychiatric and physical disorders in South Africa. J Nerv Ment Dis 2010;198(1):8-15. [http://dx.doi org/10.1097/NMD.0b013e3181c81708]

10. World Health Organization. WHO Qualityrights: Service Standards and Quality in Menta Health Care. Geneva: World Health Organization, 2014. http://www.who.int/mental_health/ policy/quality_rights/infosheet_hrs_day.pdf (accessed January 2014).

11. Griffiths H. Acute wards: Problems and solutions: Modern milieux: Therapeutic community solutions to acute ward problems. Psychiatric Bull 2002;26(10):380-382. [http://dx.doi. org/10.1192/pb.26.10.380]

12. Chikaodiri AN. Attitudes of health workers to the care of the psychiatric patients. Ann Gen Psychiatry 2009;8:19. [http://dx.doi.org/10.1186/1744-859X-8-19]

13. Aydin N, Yigit A, Inandi T, Kipinar I. Attitudes of hospital staff toward mentally ill patients in a teaching hospital, Turkey. Int J Soc Psychiatry 2003;49(1):17-26.

14. Howard L, Gamble C. Supporting mental health nurses to address the physical health need of people with serious mental illness in acute inpatient care settings. J Psychiatr Ment Health Nurs 2011;18(2):105-112. [http://dx.doi.org/10.1111/j.1365-2850.2010.01642.x]

15. Brown D, Griffiths C, Garvey F. Dedicated support in every hospital. Nurs Stand 2010;24(33):22-23.

16. Reid-Searl K, Dwyer T, Happell B, et al. Caring for children with complex emotional and psychological disorders: Experiences of nurses in a rural paediatric unit. J Clin Nurs 2009;18(24):3441-3449. [http://dx.doi.org/10.1111/j.1365-2702.2008.02567.x ]

17. Lawrence D, Kisely S, Pais J. Epidemiology of excess mortality in people with mental illness. Can J Psychiatry 2010;55(12):752-760.

18. Williams DR, Herman A, Stein DJ, et al. Twelve-month mental disorders in South Africa: Prevalence service use and demographic correlates in the population-based South African Stress and Health Study. Psychol Med 2008; 38(2):211-220. [http://dx.doi.org/10.1017/S0033291707001420]

19. South African Government. Constitution of the Republic of South Africa, 1996 (updated 2009 July 21) http://www.info.gov.za/documents/constitution/ (accessed 11 September 2013).

20. South African Government. Mental Health Care Act No. 17 of 2002. http://www.justice.gov za/legislation/acts/2002-017_mentalhealthcare.pdf (accessed July 2013).

21. Lund C, Petersen S, Bhana A. Mental health services in South Africa: Taking stock. Afr J Psychiatry 2012;15(6):402-405. [http://dx.doi.org/10.4314/ajpsy.v15i6.48]

22. Ramlall S. The Mental Health Care Act No. 17 - South Africa. Trials and triumphs: 2002 2012. Afr J Psychiatry 2012;15:407-410. [http://dx.doi.org/10.4314/ajpsy.v15i6.49]

23. Jacob KS, Sharan P, Mirza P, et al. Mental health systems in countries: Where are we now? Lancet 2007;370(9592):1061-1077. [http://dx.doi.org/10.1016/S0140-6736(07)61241-0]

24. Ramlall S, Chipps J, Mars M. Impact of the South African Mental Health Care Act No. 17 of 2002 on regional and district hospitals designated for mental health care in KwaZulu-Natal. S Afr Med J 2010;100(10):667-670.

25. American Psychiatric Association. American Psychiatric Association Practice Guidelines. http://psychiatryonline.org/guidelines.aspx (accessed 11 September 2013).

26. Sadock BJ, Sadock VA. Kaplan and Sadock's Synopsis of Psychiatry: Behavioural Sciences/ Clinical Psychiatry. 10th ed. Philadelphia: Lippincott Williams \& Wilkins, 2011.

27. Golberg D, Bidges K. Screening for psychiatric illness in general practice: The general practitioner versus the screening questionnaire. J R Coll Gen Pract 1987;37(294):15-18.

28. Margolis RL. Nonpsychiatrist house staff frequently misdiagnose psychiatric disorders in general hospital inpatients. Psychosomatics 1994;35(5):485-491

29. Leslie DL, Rosenheck RA. Use of pharmacy data to assess quality of pharmacotherapy for schizophrenia in a national health care system: Individuals and facility predictors. Med Care 2001;39(9):923-933.

30. LA Health. Your Benefits, 2013. Benmore: Discovery, 2013. http://www.lahealth.co.za/ medicalschemes_za/la_health/web/pdfs/dla_la_health_member_brochure_2013.pdf (accessed July 2013). 